\title{
Abdominal obesity is an independent predictor of serum 25-hydroxyvitamin D deficiency in adults with cerebral palsy
}

\author{
Mark D Peterson", Heidi J Haapala, Ashish Chaddha and Edward A Hurvitz
}

\begin{abstract}
Background: Individuals with cerebral palsy (CP) are at risk for nutritional insufficiency. The purpose of the study was to examine the vitamin $D$ status of adults with $C P$, and to evaluate the association between vitamin $D$ and functional level, age, race, and anthropometric indicators of adiposity.

Methods: Serum vitamin D levels, BMI, waist circumference (WC), and functional level (measured by Gross Motor Function Classification System (GMFCS)) were examined in 112 adults with CP. Vitamin D status was assessed by serum 25-hydroxyvitamin D level $(25(\mathrm{OH}) \mathrm{D})$. The influence of motor impairment and adiposity on 25(OH)D were assessed using general linear modeling and logistic regression, with age, sex, race, and season as covariates.

Results: Mean vitamin D was $28.1 \pm 16.0 \mathrm{ng} / \mathrm{ml}$. Only $45 \%$ of subjects had optimal levels of $25(\mathrm{OH}) \mathrm{D}, 21 \%$ were insufficient and $34 \%$ were deficient. Overweight or obesity was prevalent (52\%), as was abdominal obesity in men (23.5\% at $102 \mathrm{~cm}$ cutoff) and women (31.1\% at $88 \mathrm{~cm}$ cutoff). There was a robust association between the indicator of visceral adiposity $(\mathrm{WC})$ and $25(\mathrm{OH}) \mathrm{D}$ level $(\mathrm{p}<0.001)$, even after controlling for age, sex, race, season, and GMFCS. According to sex-specific WC cutoffs, the odds of being deficient in vitamin D increase by a factor of $3.5(95 \% \mathrm{Cl}$ 1.12-11.0) for abdominal obesity. GMFCS was not associated with 25(OH)D.
\end{abstract}

Conclusions: Adults with $\mathrm{CP}$ are at risk for low vitamin D levels and overweight/obesity. Waist circumference is a strong independent predictor for low vitamin D levels.

Keywords: Cerebral palsy, 25-hydroxyvitamin D, Visceral adiposity, Motor function

\section{Background}

Vitamin D plays an important role in a wide range of organ functions, and is suggested to contribute significantly to cardiometabolic and musculoskeletal health. Vitamin D deficiency is now considered to be an epidemic, with recent estimates as high as $64 \%$ of the general healthcare population [1]. At present there is substantial debate regarding the optimal level of serum 25-hydroxyvitamin D $(25(\mathrm{OH}) \mathrm{D})$ as well as the efficacy and dosing strategy of supplemental vitamin $\mathrm{D}$; however, most reports agree that serum levels less than $20 \mathrm{ng} / \mathrm{mL}$ (i.e. $50 \mathrm{nmol} / \mathrm{L}$ ) may be insufficient for optimal bone health [2]. Historically considered an independent predictor of osteoporosis [3] and

\footnotetext{
* Correspondence: mdpeterz@med.umich.edu
Department of Physical Medicine and Rehabilitation, University of Michigan

* Correspondence: mdpeterz@med.umich.edu
Department of Physical Medicine and Rehabilitation, University of Michigan Health Systems, 325 E. Eisenhower Parkway, Suite 300, Ann Arbor, Michigan 48108, USA
}

muscle function [4,5], emerging evidence has also linked vitamin $\mathrm{D}$ deficiency with a host of obesity-related comorbid conditions such as metabolic syndrome, coronary heart disease, hyperlipidemia, and diabetes [1,6,7], as well as early mortality [8]. Indeed, there is now a well-established reciprocal association between adiposity and vitamin $\mathrm{D}$, which may be caused by a decreased bioavailability of and deposition in adipose tissue compartments [9-11] (particularly in the visceral depot $[12,13])$.

The reported incidence of vitamin D deficiency is pulation specific, and contingent upon various demographic factors such as age, sex, race and geographical location (i.e., distance from the equator, and/or locations wherein foods are not fortified with vitamin D) [2]. These general characteristics notwithstanding, select sub-populations such as individuals with congenital or chronic neuromuscular disorders (e.g., cerebral palsy (CP)) 
may be at heightened risk for hypovitaminosis D-induced osteopenia and impaired bone mass accrual [14], as well as secondary health complications associated with or exaggerated by the combination of insufficient vitamin D [15], chronic sedentary behavior, and obesity [16]. Although at present the role of vitamin $\mathrm{D}$ on secondary health complications in CP is unknown, it is certainly conceivable that degree of motor impairment and abdominal adiposity may serve as significant predictors for vitamin D status.

However, most clinicians who treat patients with $\mathrm{CP}$ do not check vitamin $\mathrm{D}$ levels on a consistent basis. Considering the inherent feeding difficulties associated with esophageal reflux, swallowing, and gastric disorders, many $\mathrm{CP}$ patients have poor overall nutrition and insufficient calcium and vitamin D intake. Although a large body of research has confirmed a significant association between nutritional insufficiency, growth, and diminished musculoskeletal health in $\mathrm{CP}$, patients are also routinely prescribed anticonvulsant medications that interfere with calcium and vitamin D absorption, and that further contribute to low bone mineral density [17]. Moreover, and in combination with inadequate nutrient intake/ absorption, chronic pain and fatigue in $\mathrm{CP}$ represent two significant barriers for participation in physical activity and load bearing exercise [18], and thus dramatically increase the likelihood of being sedentary and housebound with little exposure to sunlight.

The purpose of this study was to examine vitamin D status among adults with $\mathrm{CP}$, and to determine the associations with gross motor function and several anthropometric indicators of adiposity, after adjustment for known covariates such as age, season, and race. Since degree of motor impairment is a strong indicator of nutritional insufficiency and chronic sedentary behavior, we hypothesized that vitamin D levels would be independently associated with more severe motor impairment. We also hypothesized that both BMI and waist circumference would be independent predictors of lower serum vitamin D. Certainly, understanding the independent contributions of motor impairment, as well as a modifiable predictor such as adiposity, on vitamin D status, may better define risk for latent complications which may exacerbate the CP condition.

\section{Methods}

\section{Study design}

Patient records were obtained through the University of Michigan Adult Cerebral Palsy Clinic, Department of Physical Medicine and Rehabilitation. This retrospective study included a synthesis of relevant patient descriptive data, as well as bivariate and regression analyses between various anthropometric characteristics (i.e., body mass, height, BMI, waist circumference and hip circumference, and waist-to-hip ratios), functional status, and serum vita$\min \mathrm{D}$.

\section{Patient population}

Male and female participants were 18 years and older, admitted to University of Michigan adult CP clinic. Patients in the sample represented a variety of diagnostic categories for CP, according to the Gross Motor Function Classification System (GMFCS). The initial sample consisted of 130 patients' clinic records that were eligible for inclusion in the analysis. We excluded records that did not include sufficient data pertaining to vitamin D status and/or general intake patient characteristics such as anthropometric measures. The final sample included 112 patient records (52 males, 60 females; age $=34 \pm 13.4$ years) Race/ethnicity distribution was primarily Non-Hispanic white ( 90\%), as compared to African American (8\%) and Mexican American or other Hispanic ( 2\%). Each subject signed an informed consent document and all procedures were approved by the University of Michigan Medical institutional review board for research with human subjects.

\section{Measures}

\section{Gross motor function classification system (GMFCS)}

The Gross Motor Functional Classification System (GMFCS) assesses activity limitations for gross motor function with a five level ordinal grading scale. The GMFCS in the adult population has been shown to be reliable (interclass correlation coefficient $(\mathrm{ICC})=0.93$ ) and have excellent interrater reliability (quadratic kappa value of 0.978) [19]. All patients were examined by the same physician investigator to classify GMFCS level-which was available upon chart review. The individuals were also classified into two severity categories: GMFCS levels I-III and GMFCS levels IV-V, as previously documented [20].

\section{Anthropometric measures}

As a part of normal medical intake, each patient was tested for body mass $(\mathrm{kg})$, height $(\mathrm{cm})$, and body mass index (BMI-kilograms per squared meters $\left[\left(\mathrm{kg} \cdot \mathrm{m}^{-2}\right]\right)$. For patients who had difficulty standing erect, supine recumbent length had been measured and was used instead to calculate height. Waist circumference (WC) and hip circumference $(\mathrm{HC})$ were measured using a standard Gulick tape, and evaluated to the nearest $0.1 \mathrm{~cm}$. For WC, a horizontal measure was taken at the narrowest part of the torso (i.e. below xiphoid process and above the umbilicus). Standard cutpoints for abdominal obesity in men $(>102 \mathrm{~cm})$ and women $(>88 \mathrm{~cm})$ were used, as outlined by the ATP III report. For HC, horizontal measures were taken at the site of maximal circumference. Waist-to-hip ratio (WHR) was also calculated.

\section{Vitamin D status and parathyroid hormone (PTH)}

Vitamin D levels were drawn as part of the patients' clinical evaluation. Blood samples were drawn by venipuncture 
after a 12-h fast, and assayed for serum 25(OH)D at the University of Michigan Clinical Chemistry Laboratories, in Department of Pathology. Determinations of 25(OH)D were made in serum by a chemiluminescence immunoassay (CLIA) with intra- and interassays variabilities of $4.7 \%$ and $7.1 \%$ respectively. Vitamin D status was categorized as optimal ( $\geq 30 \mathrm{ng} / \mathrm{ml})$, insufficient (21-29 ng/ml), and deficient $(<20 \mathrm{ng} / \mathrm{ml})$, based on the recommended cutpoints from the Endocrine Society [21], as well as recommendations from the Institute of Medicine (IOM) [22]. Moreover, due to the known seasonal variation of serum 25(OH)D [23], we statistically adjusted for the corresponding season of blood draw. Intact serum PTH was analyzed using a chemiluminescence assay. The reference range is $10-65 \mathrm{pg} / \mathrm{mL}$, and the interassay coefficient of variation was $<4.3 \%$ at $36 \mathrm{pg} / \mathrm{ml}$.

\section{Statistical analysis}

All statistical analyses were performed using SAS software version 9.3 (SAS Institute, Cary, NC). Descriptive characteristics were stratified by GMFCS (i.e. GMFCS I-III and IV-V). Differences between GMFCS levels were determined for general demographic and anthropometric characteristics as well as vitamin D (25(OH)D) by an independent-sample t-test, and difference in proportions for sex by Chi-square test. Pearson product-moment correlations were used to examine selected bivariate correlations. A minimum criterion alpha level of $\mathrm{p} \leq 0.05$ was used to determine statistical significance. Data are reported as means and standard deviations (SD). Linear regression was used to determine differences in vitamin D $(25(\mathrm{OH}) \mathrm{D})$ between GMFCS levels, seasons, and races. This process was completed over several steps that required creating dummy codes for each season, race, and GMFCS level (i.e., category). Thereafter, we examined vitamin $\mathrm{D}$ status for differing categories by systematically removing one category at a time (and thus creating an interchangeable reference). Using this procedure, the $\beta$ coefficient for the intercept represented the mean of the removed category, and the regression provided coefficients for each subsequent category, a standard error, a t-value, and a p-value. Partial correlation and multiple linear regression were also used to evaluate the associations between vitamin D (25(OH)D), GMFCS, and various indicators of adiposity, after controlling for multiple potential moderating factors. In addition to the predictors, the following standard covariates were included in the original model: age, sex, race, and season. A logistic model was also fitted (i.e. using the PROC LOGISTIC procedure) with explanatory variables to determine a best fit model for categorical vitamin D deficiency. Dummy coding was applied to the categorical variables (e.g., GMFCS I-III = 0, GMFCS IV-V =1). Normality of the residuals was tested using a Shapiro-Wilks test and homogeneity of the variance of the residuals was tested with standard regression diagnostics. Multicollinearity was tested using a variance inflation factor (VIF). Tests revealed no issues of collinearity for any model. Initial model testing revealed that sex was not a primary predictor of vitamin D status $(\beta=0.09 ; \mathrm{p}=0.36)$, and therefore we chose not to stratify by sex, but rather to include sex as a categorical variable in the final models.

\section{Results}

\section{Subject characteristics}

Characteristics of the study population are presented in Table 1. Of the 112 patient records that were included in the analysis, $53.6 \%$ were female $(n=60)$. GMFCS level ranged from I-V, with the following breakdown (GMFCS I: $n=9$ [8.0\%]; GMFCS II: $n=20$ [17.9\%]; GMFCS III: $n=29$ [25.9\%]; GMFCS IV: $n=29$ [25.9\%]; and GMFCS V: $n=25$ [22.3\%]. Based on traditional cut points, approximately $52 \%$ of patients were overweight or obese (i.e., $\mathrm{BMI} \geq 25 \mathrm{~kg} \cdot \mathrm{m}^{-2}$ ), and of those, $23.5 \%$ were classified as obese (i.e., BMI $\geq 30 \mathrm{~kg} \cdot \mathrm{m}^{-2}$ ). Adults with GMFCS IV-V were generally smaller in stature than GMFCS I-III.

\section{Vitamin D level}

The range for vitamin D level was from 5 to $64 \mathrm{ng} / \mathrm{mL}$ (Table 1), and correlated to both parathyroid hormone $(\mathrm{PTH})(\mathrm{r}=-0.24 ; \mathrm{p}=0.023)$ and $\mathrm{WC}(\mathrm{r}=-0.40 ; \mathrm{p}=0.002)$. Vitamin D was not correlated to age, BMI, WHR, or HC. 52 subjects (45.2\%) were considered to have optimal levels of vitamin D (>30 ng/mL); whereas $20.9 \%$ had insufficient levels (21-29 $\mathrm{ng} / \mathrm{mL})$; and $33.9 \%$ were deficient $(<20 \mathrm{ng} / \mathrm{mL})$. There were no differences in vitamin D status across levels of GMFCS $(p=0.092)$ (Figure 1). The largest seasonal difference in vitamin $\mathrm{D}$ was between winter and summer $(\beta=-4.14 \mathrm{ng} / \mathrm{mL})$, but was not significant $(\mathrm{p}=0.3067)$. African Americans had lower 25(OH)D $(\beta=-11.45 ; p=0.02)$ than Non-Hispanic white subjects.

Multiple linear regression examining predictors of vitamin D $(25(\mathrm{OH}) \mathrm{D})$ status identified WC $(\beta=-0.27$; $p<0.001$ ) (see: Figure 2 for Partial residual scatter plot) as significant, controlling for age, sex, race, season, and GMFCS (Table 2). These findings reveal that greater central adiposity is associated with lower vitamin D status, independent of motor impairment.

Logistic regression was conducted to identify the odds of being deficient at the level published by the Endocrine Society and IOM report [21,22], and revealed that for every $10 \mathrm{~cm}$ increase in WC, the odds of being deficient in vitamin D increase by a factor of 1.5 (95\% CI: 1.062 1.974). According to sex-specific WC cutoffs, the odds of being deficient increased by a factor of 3.5 (95\% CI 1.12-11.0) for abdominal obesity.

Although a dichotomous cutoff for GMFCS was used to create the motor impairment groups, 25(OH)D concentrations varied significantly. Thus, as an additional 
Table 1 Descriptive characteristics of all adults with cerebral palsy, and differences between Gross Motor Function Classification System (GMFCS) I-III and IV-V

\begin{tabular}{|c|c|c|c|c|}
\hline & Total Sample & GMFCS I-III & GMFCS IV-V & p-value \\
\hline$\overline{\mathrm{N}}$ & 112 & 58 & 54 & \\
\hline Female. O & 53.6 & 51.4 & 52.0 & 0.805 \\
\hline Age On) & $34.00(13.41)$ & $32.95(13.63)$ & $36.10(18.01)$ & 0.224 \\
\hline \multicolumn{5}{|l|}{ Race/Ethnicity, \% } \\
\hline Non-Hispanic White & 90.4 & 87.9 & 92.3 & 0.45 \\
\hline African American & 7.8 & 10.3 & 5.8 & 0.39 \\
\hline Mexican American or Other Hispanic & 1.7 & 1.7 & 1.9 & 0.94 \\
\hline Body Mass (kg) & $61.73(25.09$ & $72.35(22.51)$ & $51.024 .73)$ & $<0.001^{*}$ \\
\hline Recumbent Length (cm) & $159.21(13.35)$ & $161.65(9.90)$ & $155.68(16.27)$ & $0.043^{*}$ \\
\hline Body Mass Index $\left(\mathrm{kg} \cdot \mathrm{m}^{-2}\right)$ & $25.86(7.59)$ & $28.72(7.41)$ & $22.79(634)$ & $<0.001^{*}$ \\
\hline Obesity (BMI $\geq 30), \%$ & 23.5 & 32.1 & 14.00 & $0.04^{*}$ \\
\hline Waist Circumference (cm) & $85.53(20.48)$ & $92.80(17.47)$ & $79.20(22.14)$ & $0.003^{*}$ \\
\hline Hip Circumference (cm) & $93.75(17.23)$ & 101.19 (1 3.10) & $85.06(18.57)$ & $<0.001^{*}$ \\
\hline Waist-to-Hip Ratio & $0.90(0.09)$ & $0.90(0.10)$ & $0.90(0.08)$ & 0.74 \\
\hline 25-hydroxyvitanin D $(25(\mathrm{OH}) \mathrm{D})(\mathrm{ng} / \mathrm{mL})$ & $30.17(15.02)$ & $27.53(11.68)$ & $31.71(11.40)$ & 0.143 \\
\hline Parathvroid hormone (PTH). (pg/ml) & $49.8(26.65)$ & $47.96(25.10)$ & $52.63(28.86)$ & 0.418 \\
\hline
\end{tabular}

*Significant difference between GMFCS I-III and IV-V ( $p<0.05)$.

way to present the association between vitamin $\mathrm{D}$ and indicators of adiposity, we stratified subjects on the basis of $25(\mathrm{OH}) \mathrm{D}$ quartiles (Table 3). Subjects with higher vitamin D levels, across quartiles, had incrementally lower WC measures.

\section{Discussion}

The primary finding of this investigation is that adults with $\mathrm{CP}$ are at risk for insufficient and deficient serum vitamin D; however, vulnerability was not associated with the severity of motor impairment. It is well known that severely impaired individuals with $\mathrm{CP}$ experience significant feeding issues and are at greater risk for malnutrition, which are in-turn thought to be the primary drivers of musculoskeletal fragility and altered growth trajectories in this population. Interestingly, we found that individuals classified in the highest severity category (i.e., GMFCS V) had a similar serum vitamin D (25(OH)D)

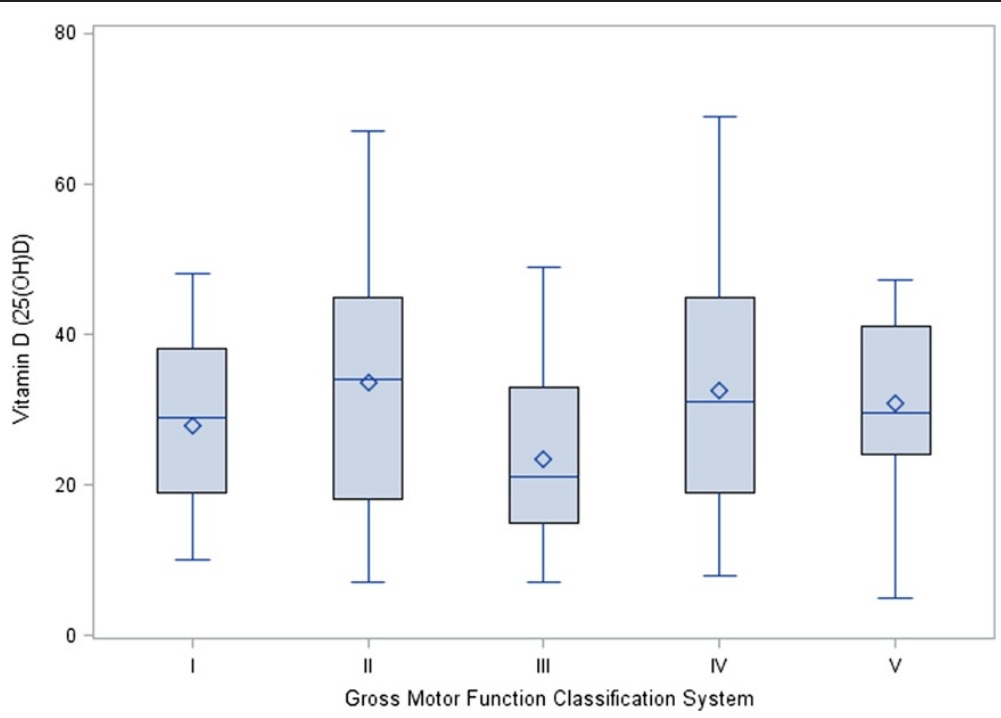

Figure 1 Comparison of mean and individual 25-hydroxyvitamin D concentrations across levels of Gross Motor Function Classification System (GMFCS). There were no significant differences between the levels as assessed by linear regression. 


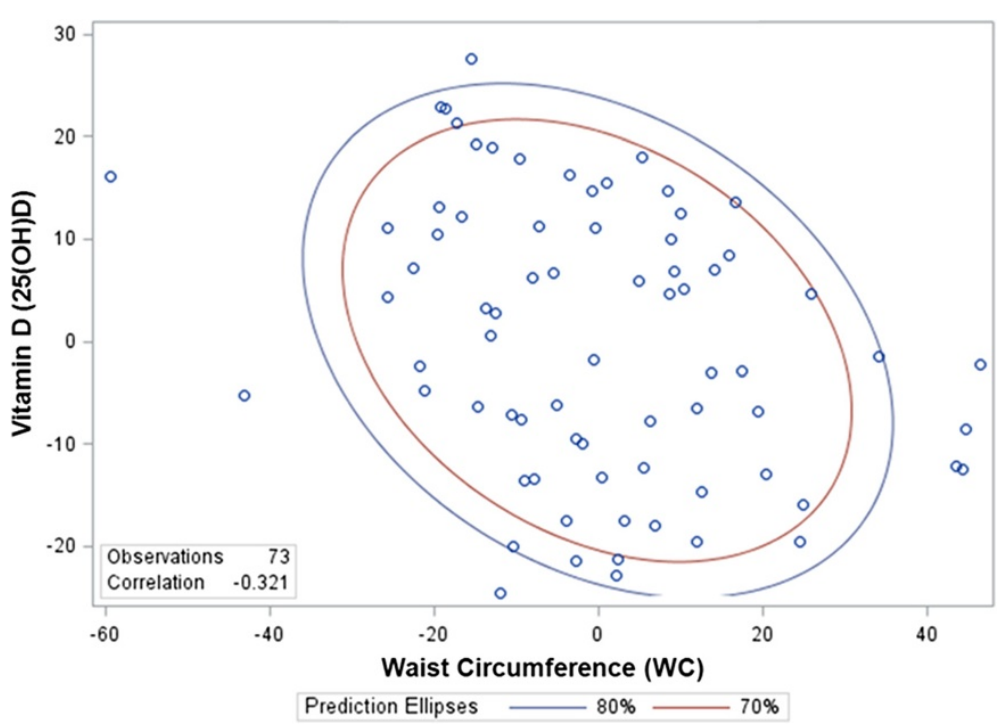

Figure 2 Partial residual scatter plot for the variables waist circumference (WC) and 25-hydroxyvitamin D after controlling for the effect of variables age, sex, and GMFCS (with $70 \%$ and $80 \%$ prediction ellipses).

status $(30.8 \mathrm{ng} / \mathrm{mL})$ as individuals in the least impaired category (i.e., GMFCS I) (27.9 ng/mL). This does not imply that severity of motor impairment is unrelated to nutrition status, growth, and/or bone health in CP; however, it does highlight an independent factor that may pose an even greater risk for vitamin $\mathrm{D}$ insufficiency. The overall prevalence of vitamin D insufficiency or deficiency was approximately $56 \%$, which is similar to the typically-developed adult population $[21,24]$. Interestingly, unlike the general population [25], BMI was not associated with serum 25 $(\mathrm{OH}) \mathrm{D}$ in this study.

Rather, abdominal obesity was the strongest predictor for serum vitamin $\mathrm{D}$ in this heterogeneous sample of adults with $\mathrm{CP}$, even after adjusting for age, sex, race, season, and level of motor function. Indeed, there is a well-established link between vitamin D deficiency, abdominal obesity and cardiometabolic risk [12,26], and yet most studies do not account for at-risk populations with severe motor disabilities. Moreover, although several studies have identified a general increased prevalence of obesity among children with CP $[27,28]$, the influence of obesity on secondary health complications has yet to be studied through the lifespan. It is of course logical to presume that the primary neurological insult associated with $\mathrm{CP}$ is the underlying cause for impaired growth and risk for musculoskeletal deterioration, but it is also likely that excessive central adiposity may lead to exaggerated risk for a non-CP, comorbid sequela as children with $\mathrm{CP}$ transition into adulthood. The current findings clearly support the need for greater clinical attention to assessments of serum vitamin D status in all patients with CP. Particular attention should also be given to individuals with $\mathrm{CP}$ who are African American, as vitamin D was significantly lower as compared to Non-Hispanic white individuals.

Moreover, children and adults with CP have significantly diminished lean body mass [29] and greater intermuscular

Table 2 General linear model to determine the independent association of functional impairment (GMFCS) and waist circumference (WC) on vitamin D status, adjusting for age, sex, GMFCS, Race and Season

\begin{tabular}{|c|c|c|c|c|c|c|}
\hline & Model predictor(s) & $\beta$ & SE & $\mathbf{t}$ & $\operatorname{Pr}>|t|$ & Adjusted $\mathrm{R}^{2}$ \\
\hline \multirow[t]{8}{*}{25 hydroxyvitamin D $(25(\mathrm{OH}) \mathrm{D})$} & & & & & & 0.19 \\
\hline & Intercept & 55.56 & 10.1 & 5.46 & $<0.001$ & \\
\hline & Age & 0.0 & 0.13 & 0.59 & 0.55 & \\
\hline & Sex & -0.66 & 3.23 & -0.20 & 0.84 & \\
\hline & WC & -0.27 & 0.08 & -3.35 & $<0.001$ & \\
\hline & GMFCS & -0.47 & 1.4 & -0.32 & 0.74 & \\
\hline & Race/Ethnicity & -11.74 & 4.02 & -2.91 & 0.01 & \\
\hline & Season & -1.56 & 1.52 & 1.02 & 0.31 & \\
\hline
\end{tabular}


Table 3 Comparison of variables in quartiles of $25(\mathrm{OH}) \mathrm{D}$ concentration

\begin{tabular}{|c|c|c|c|c|c|}
\hline & $\begin{array}{l}\text { Quartile } 1 \\
(n=27)\end{array}$ & $\begin{array}{l}\text { Quartile } 2 \\
(n=32)\end{array}$ & $\begin{array}{l}\text { Quartile } 3 \\
(n=26)\end{array}$ & $\begin{array}{l}\text { Quartile } 4 \\
(n=30)\end{array}$ & $\mathrm{p}$ value \\
\hline 25-hydroxnitamin D (25(OH)D) (ng/mL) & $11.13(3.51)$ & $22.34(3.85)$ & $34.50(3.62)$ & $49.37(8.10)$ & $\mathrm{NA}$ \\
\hline Age (yrs) & $33.67(15.6)$ & $35.98(13.87)$ & $36.06(12.56)$ & 30.35 (1 L20) & 0.317 \\
\hline Female (\%) & 44.00 & 26.67 & 18.30 & 36.67 & 0.082 \\
\hline GMFCS I-III (\%) & 29.31 & 25.86 & 25.86 & 18.97 & 0.201 \\
\hline GMFCS IV-V (\%) & 19.23 & 30.77 & 21.15 & 28.85 & 0.716 \\
\hline Body Mass (kg) & $68.31(28.3)$ & $64.86(21.37)$ & $66.94(23.28)$ & $47.62(22.79$ & 0.006 \\
\hline Recumbent Length (cm) & $158.35(12.92)$ & $159.14(8.29)$ & $161.99(16.83)$ & $157.3(15.36)$ & 0.684 \\
\hline Body Mass Index $\left(\mathrm{kg} \cdot \mathrm{m}^{-2}\right)$ & $28.90(9.9 \mathrm{M})$ & $25.22(7.23)$ & $26.51(6.18)$ & $22.81(5.47)$ & 0.052 \\
\hline Waist Circumference $(\mathrm{cm})$ & $93.75(19.06)$ & $89.56(24.73)$ & $85.68(17.01)$ & $73.95(15.60)$ & 0.012 \\
\hline Hip Circumference (cm) & $103.91(17.34)$ & $92.5(13.62)$ & $94.08(12.77)$ & $84.41(19.78)$ & 0.001 \\
\hline Parathyroid hormone (PTH). (pg/ml) & $59.32(32.87)$ & $55.32(26.83)$ & 4 L89 (21.49) & $40.84(18.14)$ & 0.036 \\
\hline
\end{tabular}

$\mathrm{p}$-value are presented to represent significant trend testing across quartiles.

adipose tissue [30], which collectively highlights the implications of skeletal muscle deterioration. Thus, even normal BMIs in this population may disguise excess body fat (i.e., "obesity misclassification" [31]), and risk for cardiovascular and metabolic dysregulation. Based on standard BMI cutoffs, our data revealed that overweight and obesity are common in adults with CP; however, BMI was not associated with vitamin D status. This is congruent with our previous work [20], and that of others [32] which demonstrates that indicators of central adiposity are potentially more sensitive for detecting standard clinical markers of cardiometabolic risk (e.g. triglycerides, HDL-cholesterol, total cholesterol to HDL cholesterol ratio, LDL-cholesterol, HOMA-IR, etc..) in adults with CP. Collectively, these findings support our ongoing contention that adults with $\mathrm{CP}$ are at higher risk for normal weight obesity and cardiometabolic dysregulation [16], and that indicators of central adiposity are superior to BMI for risk stratification. This is not surprising considering the mounting evidence in support of this diagnostic paradigm shift, even among the general population [33], and thus clinicians should be aware of the appropriate gender- and race/ethnicity-specific recommended waist circumference thresholds for abdominal obesity [34,35].

In the general population, recent data have also revealed a link between vitamin $\mathrm{D}$ and preservation of muscular strength [36]. This may have significant implications for individuals with CP over the lifespan, as even children with CP have impaired recruitment of target musculature during voluntary activity, and an overrecruitment and co-activation of antagonist musculature [37]. Premature sarcopenia and muscular weakness in CP are suggested to translate to acute functional deficit and disability [38]. As a result, functional loss, especially of mobility, is a major issue in adults with $\mathrm{CP}$. The minority of individuals that actually report preservation of mobility throughout adulthood accredit this to maintenance of strength, balance and overall fitness. It is therefore critical to gain a greater understanding of how treatment of such modifiable risk factors as vitamin D deficiency could impact long term preservation of functional capacity and activity participation.

An obvious limitation in this study is that we could not account for dietary intake of calcium or vitamin D. Thus, it is possible that more severely affected individuals were adhering to a stricter regimen of nutrient supplementation (as is commonly recommended with anticonvulsant therapies), which would explain the lack of differences across GMFCS levels. Future research should account for nutrient intake, as well as any medication that may interfere with calcium and vitamin D. Further, as with all cross-sectional investigations, a limitation of this study is the inability to disentangle the cause-effect relationship between predictors and outcomes. Perhaps just as importantly, with this design we were unable to examine numerous potential mediators that were not measured. For example, no measures of muscle strength were made, and thus although vitamin D status was not associated with GMFCS in this study, it is possible that vitamin D status may affect muscle strength differently among individuals with more severe mobility impairments. It is also plausible that vitamin $\mathrm{D}$ deficiency may lead to diminished vitamin D receptor (VDR) in type II muscle fiber (see recent review [39]), and thus have a direct influence on muscular weakness, or conversely, strength improvement, with supplementation [40].

\section{Conclusions}

This is one of the largest studies to examine vitamin D status in a heterogeneous sample of adults with $\mathrm{CP}$, and 
to determine an independent, inverse association with abdominal obesity. Further, our finding that vitamin $\mathrm{D}$ status was not linked with GMFCS is novel and important, as degree of motor impairment tends to be the clinical scapegoat of secondary problems for this population. Unfortunately, there is still a large gap between the basic research intended to uncover novel etiologic factors and treatments of $\mathrm{CP}$, and that which occurs at the translational level to understand secondary mechanisms or complications unique to this population. Clinical research tends to focus on common symptoms such as pain, spasticity, and mobility issues, and the viability and effectiveness of respective medical interventions. There has been very little attention directed at understanding the predictors of musculoskeletal pathology or cardiometabolic risk in patients with $\mathrm{CP}$ through the lifespan. Future research is certainly warranted to examine the appropriate timing and dosing of supplemental vitamin $\mathrm{D}$ in children and adults with $\mathrm{CP}$, as well as identifying optimal behavioral interventions to reduce risk of abdominal obesity.

\section{Competing interests}

The authors declare that they have no competing interests.

\section{Authors' contributions}

$\mathrm{HH}$ and $\mathrm{EH}$ carried out clinical testing and data collection. MP and AC drafted the manuscript. MP analyzed data and provided statistical interpretation. All authors read and approved the final manuscript.

\section{Acknowledgements}

Funding sources: Dr. Peterson is funded by the National Institutes of Health (1 KO1-HD074706).

Received: 12 April 2014 Accepted: 8 May 2014

Published: 19 May 2014

\section{References}

1. Anderson JL, May HT, Horne BD, Bair TL, Hall NL, Carlquist JF, Lappé DL, Muhlestein JB, Intermountain Heart Collaborative (IHC) Study Group: Relation of vitamin $D$ deficiency to cardiovascular risk factors, disease status, and incident events in a general healthcare population. Am J Cardiol 2010, 106(7):963-968.

2. Holick MF: Vitamin D deficiency. N Engl J Med 2007, 357(3):266-281.

3. Bischoff-Ferrari HA, Giovannucci E, Willett WC, Dietrich T, Dawson-Hughes B: Estimation of optimal serum concentrations of 25 -hydroxyvitamin $D$ for multiple health outcomes. Am J Clin Nutr 2006, 84(1):18-28.

4. Bischoff-Ferrari HA, Dietrich T, Orav EJ, Hu FB, Zhang Y, Karlson EW, Dawson-Hughes B: Higher 25-hydroxyvitamin D concentrations are associated with better lower-extremity function in both active and inactive persons aged $>$ or $=60 \mathrm{y}$. Am J Clin Nutr 2004, 80(3):752-758.

5. Therapeutics Committee of the Lawson Wilkins Pediatric Endocrine S, Misra M, Pacaud D, Petryk A, Collett-Solberg PF, Kappy M: Vitamin D deficiency in children and its management: review of current knowledge and recommendations. Pediatrics 2008, 122(2):398-417.

6. Pinelli NR, Jaber LA, Brown MB, Herman WH: Serum 25-hydroxy vitamin d and insulin resistance, metabolic syndrome, and glucose intolerance among Arab Americans. Diabetes Care 2010, 33(6):1373-1375.

7. Karakas M, Thorand B, Zierer A, Huth C, Meisinger C, Roden M, Rottbauer W, Peters A, Koenig W, Herder C: Low levels of serum 25-hydroxyvitamin D are associated with increased risk of myocardial infarction, especially in women: results from the MONICA/KORA augsburg case-cohort study. J Clin Endocrinol Metab 2013, 98(1):272-280.

8. Brondum-Jacobsen P, Benn M, Jensen GB, Nordestgaard BG: 25-hydroxyvitamin $\mathrm{d}$ levels and risk of ischemic heart disease, myocardial infarction, and early death: population-based study and meta-analyses of 18 and 17 studies. Arterioscler Thromb Vasc Biol 2012, 32(11):2794-2802.

9. Wortsman J, Matsuoka LY, Chen TC, Lu Z, Holick MF: Decreased bioavailability of vitamin D in obesity. Am J Clin Nutr 2000, 72(3):690-693.

10. Blum M, Dolnikowski G, Seyoum E, Harris SS, Booth SL, Peterson J, Saltzman E, Dawson-Hughes B: Vitamin D(3) in fat tissue. Endocrine 2008, 33(1):90-94

11. Earthman CP, Beckman LM, Masodkar K, Sibley SD: The link between obesity and low circulating 25 -hydroxyvitamin $\mathrm{D}$ concentrations: considerations and implications. Int J Obes (2005) 2012, 36(3):387-396.

12. Cheng S, Massaro JM, Fox CS, Larson MG, Keyes MJ, McCabe EL, Robins SJ, O'Donnell CJ, Hoffmann U, Jacques PF, Booth SL, Vasan RS, Wolf M, Wang TJ: Adiposity, cardiometabolic risk, and vitamin D status: the framingham heart study. Diabetes 2010, 59(1):242-248.

13. Freedman $B I$, Wagenknecht $L E$, Hairston $K G$, Bowden DW, Carr JJ, Hightower RC, Gordon EJ, Xu J, Langefeld CD, Divers J: Vitamin d, adiposity, and calcified atherosclerotic plaque in african-americans. J Clin Endocrinol Metab 2010, 95(3):1076-1083

14. Henderson RC, Lark RK, Gurka MJ, Worley G, Fung EB, Conaway M, Stallings VA, Stevenson RD: Bone density and metabolism in children and adolescents with moderate to severe cerebral palsy. Pediatrics 2002, 110(1 Pt 1):e5.

15. Badireddi S, Bercher AJ, Holder JB, Mireles-Cabodevila E: Vitamin D Deficiency in Patients with Neuromuscular Diseases with Chronic Respiratory Failure. Journal of parenteral and enteral nutrition: JPEN; 2013.

16. Peterson MD, Gordon PM, Hurvitz EA: Chronic disease risk among adults with cerebral palsy: the role of premature sarcopoenia, obesity and sedentary behaviour. Obes Rev 2013, 14(2):171-182.

17. Baer MT, Kozlowski BW, Blyler EM, Trahms CM, Taylor ML, Hogan MP: Vitamin D, calcium, and bone status in children with developmental delay in relation to anticonvulsant use and ambulatory status. Am J Clin Nutr 1997, 65(4):1042-1051.

18. Verschuren O, Wiart L, Hermans D, Ketelaar M: Identification of facilitators and barriers to physical activity in children and adolescents with cerebral palsy. J Pediatr 2012, 161(3):488-494.

19. Jahnsen R, Aamodt G, Rosenbaum P: Gross motor function classification system used in adults with cerebral palsy: agreement of selfreported versus professional rating. Dev Med Child Neurol 2006, 48:734-738.

20. Peterson MD, Haapala HJ, Hurvitz EA: Predictors of cardiometabolic risk among adults with cerebral palsy. Arch Phys Med Rehabil 2012, 93(5):816-821.

21. Holick MF, Binkley NC, Bischoff-Ferrari HA, Gordon CM, Hanley DA, Heaney RP, Murad MH, Weaver CM, Endocrine S: Evaluation, treatment, and prevention of vitamin D deficiency: an endocrine society clinical practice guideline. J Clin Endocrinol Metab 2011, 96(7):1911-1930.

22. IOM: Dietary reference intakes for calcium and vitamin D. committee to review dietary reference intakes for calcium and vitamin $\mathrm{D}$. In . Washington, DC: Institute of Medicine; 2011.

23. Shoben AB, Kestenbaum B, Levin G, Hoofnagle AN, Psaty BM, Siscovick DS, De Boer IH: Seasonal variation in 25-hydroxyvitamin D concentrations in the cardiovascular health study. Am J Epidemiol 2011, 174(12):1363-1372.

24. Ginde AA, Liu MC, Camargo CA Jr: Demographic differences and trends of vitamin D insufficiency in the US population, 1988-2004. Arch Intern Med 2009, 169(6):626-632.

25. Vimaleswaran KS, Berry DJ, Lu C, Tikkanen E, Pilz S, Hiraki LT, Cooper JD, Dastani Z, Li R, Houston DK, Wood AR, Michaëlsson K, Vandenput L, Zgaga L, Yerges-Armstrong LM, McCarthy MI, Dupuis J, Kaakinen M, Kleber ME, Jameson K, Arden N, Raitakari O, Viikari J, Lohman KK, Ferrucci L, Melhus H, Ingelsson E, Byberg L, Lind L, Lorentzon, M: Causal relationship between obesity and vitamin $\mathrm{D}$ status: bi-directional mendelian randomization analysis of multiple cohorts. PLoS Med 2013, 10(2):e1001383.

26. Kabadi SM, Lee BK, Liu L: Joint effects of obesity and vitamin D insufficiency on insulin resistance and type 2 diabetes: results from the NHANES 2001-2006. Diabetes Care 2012, 35(10):2048-2054.

27. Hurvitz EA, Green LB, Hornyak JE, Khurana SR, Koch LG: Body mass index measures in children with cerebral palsy related to gross motor function classification: a clinic-based study. Am J Phys Med Rehabil 2008, 87(5):395-403.

28. Rogozinski BM, Davids JR, Davis RB, Christopher LM, Anderson JP, Jameson GG Blackhurst DW: Prevalence of obesity in ambulatory children with cerebral palsy. J Bone Joint Surg Am 2007, 89(11):2421-2426. 
29. Arrowsmith FE, Allen JR, Gaskin KJ, Gruca MA, Clarke SL, Briody JN, Howman-Giles RB, Somerville H, O'Loughlin EV: Reduced body protein in children with spastic quadriplegic cerebral palsy. Am J Clin Nutr 2006, 83(3):613-618.

30. Johnson DL, Miller F, Subramanian P, Modlesky CM: Adipose tissue infiltration of skeletal muscle in children with cerebral palsy. $J$ Pediatr 2009, 154(5):715-720.

31. Peterson MD, Al Snih S, Stoddard J, Shekar A, Hurvitz EA: Obesity misclassification and the metabolic syndrome in adults with functional mobility impairments: Nutrition Examination Survey 2003-2006. Prev Med 2014, 60:71-76.

32. Ryan JM, Crowley VE, Hensey O, McGahey A, Gormley J: Waist circumference provides an indication of numerous cardiometabolic risk factors in adults with cerebral palsy. Arch Phys Med Rehabil 2014, doi: 10.1016/j.apmr.2014.03.029.

33. Katzmarzyk PT, Heymsfield SB, Bouchard C: Clinical utility of visceral adipose tissue for the identification of cardiometabolic risk in white and African American adults. Am J Clin Nutr 2013, 97(3):480-486.

34. Alberti KG, Eckel RH, Grundy SM, Zimmet PZ, Cleeman Jl, Donato KA, Fruchart JC, James WP, Loria CM, Smith SC Jr: Harmonizing the metabolic syndrome: a joint interim statement of the International Diabetes federation task force on epidemiology and prevention; national heart, lung, and blood institute; american heart association; world heart federation; international atherosclerosis society; and international association for the study of obesity. Circulation 2009, 120(16):1640-1645.

35. Alberti KG, Zimmet $P$, Shaw J: The metabolic syndrome-a new worldwide definition. Lancet 2005, 366(9491):1059-1062.

36. Grimaldi A, Parker B, Capizzi J, Clarkson P, Pescatello L, White M, PD T: 25 $(\mathrm{OH})$ vitamin $D$ is associated with greater muscle strength in healthy men and women. Med Sci Sports Exerc 2013, 45(1):157-162. doi: 110.1249/ MSS.1240b1013e31826c31829a31878.

37. Stackhouse SK, Binder-Macleod SA, Lee SC: Voluntary muscle activation, contractile properties, and fatigability in children with and without cerebral palsy. Muscle Nerve 2005, 31(5):594-601.

38. Tosi LL, Maher N, Moore DW, Goldstein M, Aisen ML: Adults with cerebral palsy: a workshop to define the challenges of treating and preventing secondary musculoskeletal and neuromuscular complications in this rapidly growing population. Dev Med Child Neurol 2009, 51(Suppl 4):2-11.

39. Pojednic RM, Ceglia L: The emerging biomolecular role of vitamin $d$ in skeletal muscle. Exerc Sport Sci Rev 2014, 42(2):76-81.

40. Pfeifer M, Begerow B, Minne HW, Abrams C, Nachtigall D, Hansen C: Effects of a short-term vitamin $D$ and calcium supplementation on body sway and secondary hyperparathyroidism in elderly women. $J$ Bone Miner Res 2000, 15(6):1113-1118.

doi:10.1186/1743-7075-11-22

Cite this article as: Peterson et al: Abdominal obesity is an independent predictor of serum 25-hydroxyvitamin D deficiency in adults with cerebral palsy. Nutrition \& Metabolism 2014 11:22.

\section{Submit your next manuscript to BioMed Central and take full advantage of:}

- Convenient online submission

- Thorough peer review

- No space constraints or color figure charges

- Immediate publication on acceptance

- Inclusion in PubMed, CAS, Scopus and Google Scholar

- Research which is freely available for redistribution

Submit your manuscript at www.biomedcentral.com/submit
Ciomed Central 